\title{
Esponsales, drudaria y amor virginal en las Cantigas de Santa María
}

\author{
Santiago Disalvo \\ Universidad Nacional de La Plata B SECRIT (CONICET)
}

Esta dona que tenno por Sennor e de que quero seer trobador, se eu per ren poss' aver seu amor, dou ao demo os outros amores.

(CSM 10, 19-22)

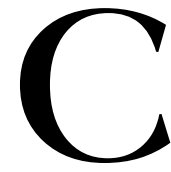

on estas palabras sella el yo lírico de las Cantigas de Santa María (CSM) su definitiva consagración al amor de una sola señora, la Virgen María, después de haber dicho en el Prólogo $B$ que "querrei-me leixar de trobar de si/ por outra dona, e cuid'a cobrar/ per esta quant' enas outras perdi" (Pról. B, 24-26). ${ }^{1}$ Hablar del amor en las Cantigas significa entender este viraje explícito en el cancionero, del amor cortés al amor mariano, lo que Joseph Snow explica como la "palinodia" del rey trovador:

This may be termed Alfonso's palinode: turning away from his former earthly ladyloves to Our Lady, he will attempt to elevate his art (trobar) to render proper praise (loor) unto her and, more important, to gain her favour. His initial objective is to declare his intention and to be allowed to woo her in this fashion. [...] There is a note again of the palinode in this latter loor [i.e. cantiga 10]: Alfonso has had other, earlier loves of an earthly nature but he is now repentant and renewed. He declares that he will abandon them all and seek a higher, more lasting reward through love of and service of the Virgin. ${ }^{2}$

\footnotetext{
${ }^{1}$ Utilizo la edición de Walter Mettmann (1986/88/89).

${ }^{2}$ SNOW, 1979. p. 308.
} 
Esto tiene su correlato en la obra prosística alfonsí, tal como ha estudiado Olga Tudorica Impey, en algunos pasajes de la General Estoria que incluyen los términos de la fin'amors occitana, utilizados para traducir e incorporar el discurso amatorio ovidiano, pero al mismo tiempo fuertemente reprobados:

¿Qué conclusión se puede sacar con respecto al reflejo de la fin'amor en la prosa alfonsí? Que es un reflejo a medias. Tal vez, para dar un tono de contemporaneidad a las fábulas ovidianas y para hacer alarde de sus conocimientos concernientes a la convención amatoria en boga más allá de los Pirineos, los colaboradores de Alfonso X hacen alusiones a ella y echan mano a algunos de sus términos. Al mismo tiempo se muestran refractarios hacia la realidad erótica que estos términos evocan. La sienten ajena y como consecuencia la tratan con ironía o desprecio. $^{3}$

En su afán por reflejar en detalle los diversos aspectos y matices de lo humano, las CSM intentan representar todas las formas del amor, desde el cariño maternal, una de las formas del amor representadas como más intensas, ${ }^{4}$ hasta el amor pasional y matrimonial. Todas las múltiples expresiones del amor quedan de alguna manera sujetas y subsidiarias del amor mariano que lo sostiene y lo domina todo. En esta breve nota señalaré algunos rasgos con que se presenta en las CSM la relación amorosa entre hombre y mujer, desde las pasiones reprobadas hasta el ideal alfonsí de consagración a la Virgen.

${ }^{3}$ IMPEY, 1985. p. 380.

${ }^{4}$ Una expresión de uso muy frecuente en estas cantigas es "mui mais ca si amava", referida al sentimiento de la madre por el hijo: "bua moura con seu fillo, que mui mais ca si amava" (205, v.39); "Est avia un seu fillo que amava mais ca ssi" (282, v.16); "Hua moller ouv' un fillo que mui mais ca si amava,/ boỹo duus doz' anos, e sempre ss' en el cataval en com' era fremosỹo, e mil vezes lo beijava/ como madr a fillo beija con que muit afan padece,//...//e faagava-o tanto quanto faagar podia." (331, vv.14-19). Sin embargo, también se aplica al amor conyugal y al amor mariano: "fillo de Maestre Pedro de Marsella, que abbade/ foi ja e tornou-se leygo; e dous fillos fremosinnos//...// De ssa moller el avia, que mui mais ca si amava."(389, vv.17-20); "Un an' en aquela terra foi mui caro, com' oy, / e hua moller mui bõa, que amava mais ca si/ a Virgen Santa Maria"(258, vv.10-12), respectivamente. En todos los casos, los subrayados son míos. 


\section{El rey trovador y el lenguaje de la fin'amors}

El amor pasional es evidentemente identificado en el cancionero con el léxico cortesano proveniente de la fin'amors occitana. Si bien éste es un concepto que ha sido largamente discutido, criticado y aun puesto en duda por los medievalistas a lo largo del siglo XX (junto con su equivalente francés amour courtois), ${ }^{5}$ es imposible negar en la obra alfonsí la influencia de, por lo menos, un vocabulario y una cierta forma de expresión propia de la lírica amorosa trovadoresca. Cabe recordar, en palabras de Carlos Alvar, que la práctica literaria (¿y extraliteraria?) de la llamada fin'amors había llevado a una conceptualización específica y a una gradación de la experiencia amorosa:

Los mismos poetas dan muestras, con frecuencia, de los distintos avances que han experimentado en el terreno amoroso; en este sentido, debemos observar que el análisis que se hace de la pasión amorosa en los versos de los trovadores lleva a establecer distintos grados y serían (según un autor anónimo de mediados del siglo XIII):

\footnotetext{
${ }^{5}$ En 1936, C. S. Lewis afirmaba de forma categórica: "Todo el mundo tiene referencias del amor cortesano, y todos saben que aparece de súbito en el siglo $\mathrm{XI}$ en Languedoc. [...] El sentimiento que expresa es, por supuesto, el amor; pero un amor de especie muy particular cuyas características serían: la humildad, la cortesía, el adulterio y la religión del amor." (LEWIS, 1969. p. 2). Más de tres décadas más tarde, arguye Keith Whinnom en su estudio preliminar a Cárcel de amor de Diego de San Pedro: "Corre aún bastante divulgada la idea de que el amor romántico o novelesco - por no decir ya 'el amor cortesano' o 'cortés' data de los finales del siglo XI y se origina en Provenza. Lo han dicho muy claramente Curtius, Lewis, Bezzola y muchos más, y es un lugar común de las historias de la literatura..." (WHINNOM, 1971. p. 8). Y, más adelante, tratando acerca de la aplicabilidad del término "amor cortés" a la poesía cancioneril castellana y a la narrativa sentimental del siglo XV, este autor continúa: "Pero cada uno de los criterios de Lewis, tanto como de Gaston Paris o de Lot-Borodine o del padre Denomy, se puede rebatir o disputar o limitar. Ninguna de estas proposiciones encontraría hoy día una acogida general. Nos han hecho recordar que el término mismo no es más que una traducción de 'amour courtois', expresión popularizada por Gaston Paris en el siglo XIX. Tampoco nos aprovecha el empleo del provenzal 'finamors', porque aun en la lírica primitiva de los trovadores no tiene un sentido muy claro..." (WHINNOM, 1971. p. 16).
} 
fenhedor, cuando el enamorado no se ha atrevido a manifestar sus sentimientos; pregador, si le ha expresado a la dama su amor; entendedor: la dama le acoge con buena cara, le hace caso y premia al enamorado con sonrisas y diversas prendas; drutz, si "lo acoge bajo sus mantas". ${ }^{6}$

Podemos afirmar, pues, considerando los estudios de Impey (prosa histórica) y de Snow (cantigas de loor) que en el discurso alfonsí están presentes los cuatro grados del amor - fenhedor, pregador, entendedor, drutz -, según el código trovadoresco occitano.

No caben dudas de que Alfonso X y su scriptorium han abrevado de la corriente misma de la trovadoresca occitana, además de la autóctona de los segreles gallegos y portugueses (representada en ese momento, entre muchos otros, por Men Rodrigues Tenoiro, Airas Nunes, Gonçalo Eanes do Vinhal, Pero da Ponte, Bernaldo de Bonaval). Entre los occitanos, se encuentran exponentes como Bonifaci Calvo, Folquet de Lunel, Guilhem de Montanhagol, Bertran d'Alamanon, Cerverí de Girona, Guiraut Riquier (considerado el último trovador, como él mismo insinúa: "mas trop suy vengutz als derriers"), muchos de ellos refugiados en la corte castellana, después de un período de convulsivos acontecimientos en el Mediodía de Francia. El vínculo entre éstos y Alfonso X es muy estrecho, tanto que Guiraut Riquier dirige, como poeta, su súplica al rey, la célebre Suplicatio que fe Guirautz Riquier al rey de Castela per lo nom de joglars, ${ }^{8}$ con la consiguiente respuesta que supuestamente dicta el monarca, la Declaratio en la que se establecen la jerarquía y las funciones sociales de juglares y trovadores. La fluidez del intercambio literario entre la poesía trovadoresca amatoria y la lírica mariana alfonsí, reviste una enorme importancia. Existen, por ejemplo, varias composiciones en las que se han "traducido" el lenguaje y la forma de las albas amorosas a la alabanza de la Virgen. Tal es el caso de la cantiga de loor 340, cuya filiación lírica y melódica puede identificarse claramente en el alba provenzal S'anc fui bela ni prezada del trovador Cadenet. Otro trovador de esta generación de "últimos trovadores" situados bajo el signo de María y acogidos en la corte alfonsí, es el catalán Cerverí de Girona, el cual vino acompañando al infante don Pedro de

${ }^{6}$ ALVAR, 1999. p. 44-45.

${ }^{7}$ Se trata del último verso de su poema Be.m negra de chantar tener, citado en RIQUER, 1975. p. 1610. 
Aragón, en 1269, quien se había de entrevistar con su cuñado Alfonso en Toledo [...] En esta ocasión el trovador catalán compuso una "Canço de Madona Santa Maria", en la que se dirige al rey castellano, diciendo:

Reys castelas, tota res mor e fina

mas non o fay la domn'on vos chantatz.?

Por otro lado, es necesario recordar las cantigas de amor del mismo Alfonso X, dentro del corpus de las llamadas "cantigas profanas", si bien se trata sólo de cuatro poemas - a saber, Par Deus, senhor; Pois que m'ei ora d'alongar; Ben sabia eu, mha senhor; Senhora, por amor Dios (esta última en castellano y, según Lapesa, paródica). ${ }^{10}$ Más allá de la cuestión de la sinceridad poética del rey, lo cierto es que la única senhor verdaderamente identificable en la lírica alfonsí es la Virgen María y, por lo demás, sus cantigas de amor profanas tienden a ser más bien convencionales. En cambio, las de loor de Santa María revelan un dramatismo que es lícito calificar como más verosímil, en todo caso equivalente al de la cantiga "profana" Non me posso pagar tanto, "cantiga de change"11 en la que el rey suspira y se queja por el ataque constante de sus enemigos. ${ }^{12}$ Posiblemente, la palinodia de la que habla Snow se refiera al abandono de esta actividad poética "profana" y convencional, aunque algunos autores como Valeria Bertolucci Pizzorusso discrepen en cierta medida en este asunto, al menos considerado en su perspectiva cronológica. ${ }^{13}$

\footnotetext{
${ }^{8}$ Ver BERTOLUCCI, 1966.

${ }^{9}$ MONTOYA MARTÍNEZ, 1995. p. 26.

${ }^{10}$ Ver PAREDES NÚÑEZ, 1988. p. 77.

${ }^{11}$ Martha Schaffer intenta identificar una serie de motivos asociados con el change (llanto, queja), empleada en las cantigas de amor, que se extiende al cancionero marial alfonsí. (Schaffer, 1999).

${ }^{12}$ Considerada por los críticos una pieza maestra de Alfonso X: "Especial relieve tiene la cantiga "Non me posso pagar tanto" (CBN. 480; CV. 63), sin duda alguna una de las más bellas composiciones del Rey Sabio, capaz por sí sola, en opinión de Rodrigues Lapa, de colocar al autor regio como uno de los mayores poetas de la lírica gallego-portuguesa” (PAREDES NÚÑEZ, 1988. p. 13).

${ }^{13}$ Asevera la filóloga italiana: "Non è pensabile che tale bipartizione tra poesie profane e poesie mariane sia trasferibile nella sua nettezza anche nell'iter biografico dell'attività poetica alfonsina: il che significherebbe riferire al periodo giovanile tutta l'irrriverente poesia profana, e in quello della maturità e vecchiaia
} 
En este sentido, el lenguaje de la queja y del padecimiento (la coita de las cantigas de amor) irrumpe en las CSM para enfatizar el vínculo amoroso con la Virgen y el urgente deseo de salvación:

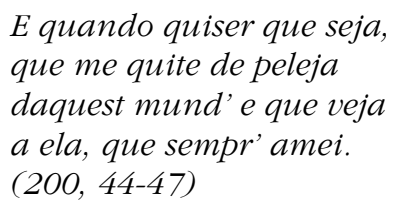

Poren lle rogo que por ben tenna

que, quando for que a mia morte venna, que a mia alma non se detenna

d'ir a logar u a sempre veja.

(280, 24-27)

E poren, Sennor onrrada, ta mercee en mi seja que me leves $u$ te veja daquesta vida mesqũa. (310, 31-34)

Equerria

t'eu ver con el, ca seria quito de maa ventura e metudo na folgura $u$ es con Deus, $u$ es alva. (340, 66-70)

E queredes que vos veja ali $u$ vos sodes, quando me for daqui.

(402, 28-29)

La súplica, transformada ahora en un pedido de rescate, se tiñe de esa nostalgia por el amor ausente, tan propia de la lírica gallego-portuguesa. Como en las cantigas de amigo, el yo canta en soledad su deseo de reunirse con el amado lejano; canta "en esta orilla" su deseo por lo que está "del

la poesia religiosa mariana. E ciò non sembra giusto anzitutto perché c'è il pericolo di ricalcare in questo modo un vecchio stereotipo letterario (la parabola della saggezza raggiunta dal senex, che ripara ai suoi giovanili "errori")" (BERTOLUCCI, 1999. p. 152). 
otro lado", en la orilla que no puede ver y de la cual sigue esperando una manifestación. Así lo expresa, por ejemplo, el sacerdote alemán en el final de la cantiga 149: "Eu te rogo,/Sennor, que tu me leves desta carcer escura/ / E que veja no Ceo a ta face velida", utilizando incluso un adjetivo tan caro a los poetas de las cantigas de amigo. Estas expresiones melancólicas y pedidos de rescate, que se intensifican en la segunda mitad del cancionero, y sobre todo hacia el final (como lo demuestra la cantiga de cierre 402), brotan en diferentes momentos de la trayectoria lírica del yo autoral, como el aflorar de la subjetividad del rey trovador.

En las CSM, el trovador es, pues, entendedor (cantiga 130) de una dama a quien ha de amar de forma preferencial o, mejor aún, exclusiva (Pról. B, 10), y a la cual está ligado por un vínculo de serviço, que espera ver recompensado en algún momento con un gualardon (400, 401). Los términos occitanos drutz, entendemen, midons (o domna), guizardo ("premio" o "trofeo"), provenientes del código de la fin' amors, son asimilados en el discurso de las Cantigas y traducidos con un nuevo valor referencial. Así, Alfonso puede ser el entendedor ("amante aceptado por su dama") de la Virgen, pero su condición de amante no es una esclavitud que le impone su dona y sennor, sino un servicio de devoción y alabanza, mediante el cual implora el galardón de la salvación. Se subvierte aquí el modelo del amor cortés: para el trovador mundano la amada muestra una actitud altiva, apartada, llena de orgullo y desdén puesto que, como meta deseada, la dama es inalcanzable y, por tanto, fuente de sufrimiento para su poeta-amante:

As outras nos fazen muit' esperar
polo seu ben e por el lazerar,
mas esta non quer con seu ben tardar
e dá-nos ben d'outros bẽes mayor.
$(130,29-32)$

En el comentario a la cantiga 130, en su edición de las cantigas de loor, Elvira Fidalgo nos recuerda que: "Esta cantiga é, quizáis, a mellor mostra da adaptación da cantiga de amor da lírica profana á cantiga de loor en todo o corpus afonsino". ${ }^{14} \mathrm{El}$ estribillo, "Quen entender quiser, entendedor/ seja da Madre de Nostro Sennor", y la primera estrofa, con una clara alusión al penúltimo grado de la fin'amors, remiten, según esta autora, al entendimento expuesto en el Prólogo B como requisito del ben trobar

\footnotetext{
${ }^{14}$ FIDALGO, 2003, p. 176.
} 
("Porque trobar é cousa en que jaz/ entendimento, poren queno faz/á-o d'aver...", vv. 3-4). El loor 130 describe a la Virgen en contraposición con las "otras damas", "coa mesma técnica que nos permitía erguer a imaxe daquela muller altiva da cantiga de amor: o seu comportamento con respecto ao namorado", ${ }^{15}$ estableciendo un encadenamiento de tópicos y registro con los otros loores del cancionero. ${ }^{16}$

En conclusión, considerando la evolución del yo lírico en las cantigas de loor, se puede sintetizar que el anuncio del nuevo trobar y todo su programa poético (Pról. B) cede el paso a la palinodia (cantigas 1 y 10), para entrar luego en una serie conformada por un centenar de "bimnos" (20-110); a estos les suceden las cantigas de exhortación a los trovadores que, con algunas excepciones, abarcan desde la 120 hasta la 310; finalmente se retoma la alocución al tú poético (María) como en la primera parte, para terminar con las peticiones finales (400, 401, 402), más intensas y urgentes que las del inicio, y centradas en el gualardon.

\section{El amor en los milagros}

También en las cantigas narrativas, Alfonso es presentado como un trovador, tanto en primera como en tercera persona. El narrador dice de él: "demais trobava per ela [María], segund' oý departir" $(295,20)$ y la rúbrica de la cantiga 348 lo presenta como "uu rey que trobava por ela". También en la cantiga 279 (un "cuasi-loor") la voz de Alfonso se dirige a la Virgen llamándose a sí mismo "vosso trobador". Teniendo en cuenta la naturaleza de la representación de rey-trovador en la perspectiva de su "(auto)biografía espiritual", según el concepto de Snow ya mencionado, es conveniente aquí subrayar que esta representación se encuentra perfectamente ligada al significado último de todos los demás aspectos biográficos: Alfonso es de la Virgen. ${ }^{17}$ Todos los personajes biográficos que la narración presenta positivamente también lo son, sirviendo a Alfonso en la corte o en la

\footnotetext{
${ }^{15}$ FIDALGO, 2003, p. 176

${ }^{16}$ FIDALGO, 2003, p. 177.

17 "It is a personal response to her loyalty to him. If he fails as a sinner, he will make up some lost ground as a worthy singer; and this is the fact that Alfonso never seems to lose sight of in those cantigas that carry the narrative of his troubadouresque quest for life's highest reward: salvation" (SNOW, 1990. p. 129).
} 
guerra, por oposición a los enemigos del reino o de la persona misma del rey, de los cuales toma venganza con la ayuda de la Virgen:

Aqueste [Alfonso] Santa Maria mui de coraçon de pran loava mais d'outra cousa, e non prendia affan en servi-la noit' e dia, rogando seu bon talan que morress' en seu serviço, poi-lo seu ben nunca fal. [...]

E depois de muitos maes o sãou, grandes e greus, que ouve pois en Castela, u quis o Fillo de Deus que fillasse gran vingança daqueles que eran seus ẽemigos e pois dele. ... $(235,10-13.70-73)$

Enton el Rei Don Affonso, fillo del Rei Don Fernando, reinava, que da Reynna dos ceos tiia bando contra mouros e crischãos maos, e demais trobando andava dos seus miragres grandes que sabe fazer. (345, 11-14)

En las cantigas narrativas encontramos personajes que, de alguna manera, ilustran el "estado previo" del rey Alfonso, antes de su palinodia: son espejos del rey. En la cantiga 16, por ejemplo, un caballero que ama a una mujer hermosa llega al extremo de la desesperación y de la locura al no verse correspondido por ella. Luego la Virgen se le aparece mientras está rezando y le muestra su belleza, que supera a la de su amada. Entonces,

O cavaleiro disse: "Sennor, Madre de Deus, tu es a mais fremosa cousa que estes meus ollos nunca viron; poren seja dos teus servos que tu amas, e quer a outra leixar." (16, 70-73)

Es posible aquí oír el eco de la cantiga 10, en la que se encuentra la decisión del yo lírico de dejar "os outros amores" por el amor de María, que está lleno de bienes para sus amantes.

En otras cantigas, más que liberar de un amor pasional, lo que hace la Virgen es curar a los lujuriosos de su vicio. Tanto caballeros como clérigos y monjes (en las cantigas 137, 151, 152) piden a María ser fortalecidos para no caer de nuevo en el pecado de lujuria. La Virgen los cura de la misma forma que sana a otros que están enfermos, haciendo que ordenen su ímpetu amoroso hacia ella: 
Those who have acknowledged her superior beauty and purity and called on her to protect them can be confident of her aide, but must also realize that are bound to her. She responds to their needs without fail, but requires that they fulfill their promises to her". ${ }^{18}$

Dentro de la terminología cortesana, adquiere especial importancia la palabra drudaria, el cuarto grado del fin'amador, el que ha sido recibido y correspondido (incluso físicamente) por su amada. En el cancionero, la palabra se utiliza en la cantiga 11 para referirse a los amores de un monje que: "cada noyt' en drudaria/ a bua sa druda ýa/con ela tẽer/ seu gasallado" (11, 19-22). Por lo tanto, drudaria designa una relación adúltera en esta instancia del cancionero, ${ }^{19}$ y en consonancia con la significación que se le otorga al término en la prosa alfonsí, ${ }^{20}$ aunque al final del cancionero asistiremos a su resignificación. El amor adúltero es reprobado no tanto por entrañar el pecado de lujuria, sino porque se opone al cumplimiento de un legítimo compromiso amoroso previo. Se trata, como se verá, de una deformación del amor, porque es presentada en contra de la lealtad a un vínculo amoroso ya asumido.

${ }^{18}$ POWELL JAYNE, 1991. p. 119. En su estudio, la autora analiza las cantigas 125 , 132, 151 (clérigos) y 16, 137, 152 (laicos)

${ }^{19}$ Es sugestivo el antiguo significado latino, que implica el vínculo legal entre un hombre y la mujer de su señor: "drudaria, drudairia (<drudis): une redevance due à l'épouse du seigneur haut-justicier - a payment due to the wife of a lord possessing high jurisdiction. [Donatio] per drudairiam ad fevum"; siendo el "drudis, drudus, drusius (germ.) conseiller, homme de confiance - intimate counsellor" (Cfr. NIERMEYER, 1984. p. 360).

${ }^{20}$ Aclara Olga T. Impey: "Que el amor profesado por los trovadores no halla aprobación alguna entre los colaboradores alfonsíes se ve también del sentido totalmente despectivo que dan a la voz drut, que se refiere al amante galardonado por su domna. En el vocabulario trovadoresco, el término drutz es ambivalente: acompañado de epítetos como fis o leial designa al finamador, empleado sin epítetos se refiere al amant charnel. En sus comentarios, los traductores alfonsíes acentúan todavía más la degradación semántica de drut, o en castellano drudo, que en las estorias de Alfonso es un mero sinónimo de ‘adúltero' [...] Asimismo, en la prosificación de la cantiga XI del Rey Sabio, la del monje que iba 'cada noyt' en drudaria a bua sa druda ýa/ con ela tẽer seu gasallado, "el prosificador traduce drudaria por 'yerro de luxuria'." (IMPEY, 1985. p. 379). 
Como hemos visto hasta aquí, la crítica sobre CSM ha destacado en varias oportunidades la presencia de la forma de relación amorosa en términos corteses. Sin embargo, el ideal del cancionero puede comprenderse solamente si se tiene en cuenta también la forma del amor matrimonial representada en varios de los milagros. María es una tenaz defensora del matrimonio y de los compromisos asumidos en los esponsales. La cantiga 135, por ejemplo, cuenta la historia de dos jóvenes que, habiéndose criado juntos, se juraron amor para siempre en nombre de la Madre de Dios, "assi que ambos por seus/ ficaron" (135, 33-34). Los padres, que se oponían a este amor, determinaron separarlos, lo que acarrea una trama "novelesca" de obstáculos, entre los cuales figura el casamiento ilegítimo de la doncella, y el peligro de perder la virginidad fuera del matrimonio legítimo. En esta ocasión, la muchacha replica a su agresor:

\title{
E non é guisado
}

de me forçardes vos, non,

ca à Virgen dei en don

meu corpo, tenp' á passado.

...

Poren nunca mi averá

erg' a quen m'ela dará

(135, 93-97)

La cantiga finaliza con el feliz reencuentro y casamiento de los prometidos, y no omite la mención de su consumación mediante el acto sexual en la noche de bodas:

\author{
E logo tost' e viaz \\ fezeron vodas assaz \\ onrradas e muit' en paz; \\ e pois ouveron jantado, \\ o novio fez como faz \\ novio a novia en solaz; \\ e assi foi acabado. \\ (135, 152-158)
}

En cuanto a la defensa del matrimonio, también cabe mencionar la cantiga 216 en la que la Virgen evita la deshonra de una mujer (haciéndose pasar por ella) a quien su marido ha entregado al demonio, como parte de un desesperado pacto para salir de la pobreza. En todos los casos, se insiste en que la Virgen guarda de peligro "a los suyos", es decir, a quienes le han prometido devoción y a los que ella ha tomado para sí. 
Existen otras dos cantigas similares a éstas, la 84 y la 241, en las que María salva y protege a un matrimonio y a unos jóvenes prometidos, pero que se destacan de las demás porque culminan con la decisión conjunta de esposo y esposa, o prometido y prometida, de "tomar orden", es decir, de entrar en la vida consagrada. Esto nos permite establecer un nexo de capital importancia entre el matrimonio y el alto número de cantigas dedicadas a la defensa de los votos a la vida virginal.

Santa María aparece como protectora y guía de los clérigos, monjes y monjas que se alejan de sus votos: la abadesa preñada que es defendida (cantiga 7); la monja embarazada que es reemplazada temporalmente por María en el monasterio (55, similar a la 94); las monjas disuadidas de escapar con sus amantes ( 58 y 59); la mujer a quien se le perdona el adulterio y los múltiples filicidios y que, salvada del suicidio, finalmente se consagra (201), entre muchas otras. La defensa de la vocación virginal no consiste tanto en evitar el pecado de lujuria, cuanto en disuadir de la deserción. Los pecados son perdonados: se trata de que el fiel vuelva a la comunidad vocacional que había decidido abandonar.

Ahora bien, es evidente que el amor virginal adquiere la formulación del matrimonio, es decir, tiene una dimensión de nupcialidad. La Virgen María demuestra ser defensora aguerrida de los votos virginales, considerándolos un vínculo de fidelidad y amor indisoluble con su propia persona. La evidencia mayor se encuentra en la representación de su actitud como la de una esposa celosa. Un claro ejemplo es la cantiga 132, en la que María se aparece a un clérigo, que habiéndole prometido total consagración, acaba tomando en matrimonio a una doncella. Para reclamarle el cumplimiento de su voto, como una novia celosa, María le reprocha:

Non es tu o que dizias

que mi mais que al amavas

e que noytes e dias

mui de grado saudavas?

Porqué outra fillar yas

amiga e desdennavas

a mi, que amor ti avia?

...

Demais saudar-me vẽes pois que te de mi partiste;

en todo torto me tẽes,

di, e porqué me mentiste?

Preçaste mais los seus bẽes 
ca os meus? Porqué feziste, sandez, tan grand' ousadia? $(132,101-115)^{21}$

Se trata del motivo del sponsus marianus, que aparece reiteradas veces en las colecciones de milagros y en las CSM en particular. Una formulación interesante de este motivo aparece en la cantiga $42,{ }^{22}$ cuyo tema reaparece, ya en la modernidad, bajo otras formas en un cuento de Prosper Merimée, "La Vénus d'Ille". ${ }^{23}$ Un mancebo enamorado, que traía el anillo de su amiga, llega con unos amigos a jugar pelota en una plaza. Por miedo a perder o romper el anillo, decide ponerlo en el dedo de la estatua de la Virgen, de cuya belleza queda enamorado al instante y a la cual promete

${ }^{21}$ Esta increpación aparece también en otras versiones del milagro, como las de los mss. Thott 128 o BN110: "O inique et stultissime hominum. Cur me dereliquisti cum tua amica essem, illaqueatus in alterius amorem? Nunquid alteram invenisti [me] meliorem? Moneo te ne me delrellinquas ne me contempta alteram uxorem ducas." (GERLI, 1989. p.237, y BAÑOS VALLEJO, 1997. p.301); o bien la de los Milagros de Nuestra Señora de Berceo (XIII): "Don fol malastrugado, torpe e enloquido,/) en qué roídos andas? ) en qué eres caido?/Semejas ervolado, que as yervas bevido,/ o que eres del blago de Sant Martín tannido.// Assaz eras varón bien casado comigo,/ yo mucho te quería como a buen amigo;/ mas tú andas buscando mejor de pan de trigo,/ non valdrás más por esso quanto vale un figo.//Si tú a mi quisieres escuchar e creer,/ de la vida primera non te querrás toller:/ a mi non dessarás por con otra tener,/ si non, avrás la lenna a cuestas a traer" (coplas 340-342; GERLI, 1989. p.130).

${ }^{22}$ Las fuentes más antiguas del relato se remontan a Guillermo de Malmesbury (hacia 1140): "The earliest version, found in William of Malmsbury's De Gestis Regum Anglorum (c. 1100) deals with a statue of the goddess Venus. This deity, regarded in the Middle Ages as a kind of wicked fairy or demon, appeared in a number of books. [...] Malmsbury's story of Venus contains most of the details found in later versions. A young man, before taking part in a ball game, removed from his finger a ring and placed it upon the finger of an ancient Roman image of Venus. [...] Certain other elements of Malmsbury's tale failed to influence later writers, but the ones mentioned lived on with surprising vitality. King Alfonso's rendition belongs definitely to the tradition begun with Malmsbury, although the statue in the Spanish king's book is that of the Virgin and not of the pagan goddess." (Keller, 1959: 455).

${ }^{23}$ Ver ASENSIO, 1985. 
lealtad. La estatua encoge su dedo, sellando así el voto del joven. Más tarde éste retornará junto a su amiga, pero, ante la promesa incumplida, la Virgen no tardará en reclamar:

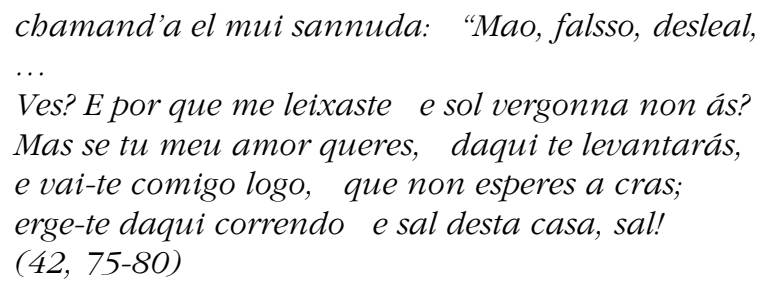

Una de las fuentes de esta cantiga, el milagro 21 del libro I de Miracles de Nostre Dame de Gautier de Coinci, permite entender cabalmente el concepto de sponsus marianus, al explicar la consagración a María, a través de un juego de palabras, en contraposición al "malmaridaje":
Moines et clers qui se marie
A ma dame sainte Marie
Mout hautement est mariez,
Mais cil est trop mesmariez
Et tuit cil trop se mesmarient
Qui as Marïons se marient.
Par Marïons, par mariees
Sont mout d'ames mesmariees.
Por Dieu, ne nos mesmarions!
Laissons Maros et Marïons,
Se nos marions a Marie,
Qui ses maris ou ciel marie.
(vv. 185-196)

Este "malmaridaje", que implica desposar a un hombre o a una mujer común (designados con los nombre populares, "Marot" y "Marion"), sirve para ensalzar el "alto matrimonio" - mariano - que es la vida monástica.

\section{El drudo como sponsus marianus}

El motivo del sponsus marianus, reforzado mediante el motivo del anillo entregado a la estatua, sugiere interesantes puntos de contacto con la vida de Alfonso X, cuyo modelo es la de su padre Fernando III. Al igual que el clérigo enamorado de la cantiga 42, en la 292 el espíritu del 
fallecido rey santo decide, en una aparición, que la sortija que había sido suya pase a la mano de una imagen de Santa María, consagrando así su amor a ella. El texto retrata a los padres de Alfonso X, San Fernando y Beatriz, con un marcado estilo hagiográfico al mencionar la consagración del matrimonio real a la Virgen, cuyo signo visible es la incorrupción de los cuerpos ya sepultados:

Ond'avẽo que seu fillo, Rei Don Alfonso, fazer
fez mui rica sepoltura que costou mui grand' aver,
feita en fegura dele, polos ossos y meter
se o achassen desfeito; mas tornou-xe-lle en al.
..
Ca o achou tod' enteiro e a ssa madre, ca Deus
non quis que sse desfezessen, ca ambos eran ben seus
quites, que nunca mais foron San Marcos e San Mateus,
outrossi da Santa Virgen, que do mund'é estadal.
(292, 41-49)

Se ve así, entonces, como el motivo del sponsus marianus vuelve, con un matiz adicional de significado, al terreno del amor matrimonial, con el objeto de expresar la consagración del rey.

Como ya se ha visto, los caballeros enamorados y otros amantes que aparecen en los poemas constituyen los "espejos alfonsíes" del pasado implícito de Alfonso X en el cancionero. Los "outros amores" de la cantiga 10 y las "outras donas" de la 130, por las que tanto perdió (tal como aclara en el Prólogo B), representan la antigua instancia abandonada por Alfonso para dedicarse totalmente a María. En el cancionero, él se presenta como entendedor de la Virgen, es decir, aquel enamorado a quien la Dama ha aceptado y a la cual está ligado por un vínculo de servicio, que espera ver recompensado en algún momento con un galardón. Pero el entendedor no es el último grado en la escala amorosa.

A Fernando III, presentado en el cancionero mediante un discurso hagiográfico, ya se le ha concedido el grado de drudo, formulado ahora como sponsus marianus, mientras que Alfonso es aún entendedor de la Virgen. La drudaria, el estado del amante recompensado con un galardón, había adquirido un significado negativo al inicio del cancionero (cantiga 11), pero hacia el final se resignifica, tal como lo explica Snow:

The final stage of drut is the one to which he may only metaphorically aspire, of course, such spiritual union being possible only with salvation. That the troubadour is anxious to enjoy such favour seems 
indicated by the frequent projections of himself into situations where be will be gazing on Mary's radiant face. The only drut of Mary is God Himself, a fact which the poet of CSM 413 acknowledges in bis fourth stanza: 'e ben semella de Deus tal drudaria'.24

En clave alfonsí, el entendedor es el devoto amante de María, pero drudaria sólo puede ser la de Dios, único ser a quien María se entrega totalmente:
Mas aquesta Virgen amou Deus atanto
que a enprennou do Espirito Santo, sen prender end' ela dano nen espanto; $e$ ben semella de Deus tal drudaria.
$(413,20-23)$

En este intento de trascender los conceptos del amor cortés, mediante la resignificación de su vocabulario, Alfonso acaba por plantear la drudaria (que, por extensión, es la de todos los que ya están en la gloria de Dios) como consagración: la de María, la sponsa Dei que se entrega virginalmente, y la del hombre, sponsus marianus, que se consagra a ella, en una suerte de tenson trovadoresca de fuerte base doctrinal, que evidencia mucho más que un ejercicio retórico.

\section{Bibliografía}

ALVAR, Carlos (Ed.). Poesía de Trovadores, Trouvères y Minnesinger [Edición bilingüe]. Madrid: Alianza, 1999.

ASENSIO, Jaime. La cantiga XLII de Alfonso x y la Vénus d'Ille de Mérimée: polarizaciones de un tema. Revista Canadiense de Estudios Hispánicos, IX, 3, p. 451-463, 1985.

BAÑOS VALLEJO, Fernando (Ed.). Gonzalo de Berceo. Milagros de Nuestra Señora, [Apéndice: Fuente latina, según el texto del ms. 110 de la Biblioteca Nacional de Madrid]. Barcelona: Crítica, 1997.

BERTOLUCCI PIZZORUSSO, Valeria. La Supplica di Guiraut Riquier e la risposta di Alfonso X di Castiglia. Studi mediolatini e volgari, XIV, p. 10-135, 1966.

${ }^{24}$ SNOW, 1979. p. 311. 
BERTOLUCCI PIZZORUSSO, Valeria. Alfonso X el Sabio, poeta profano e mariano. MONTOYA MARTÍNEZ, J.; DOMÍNGUEZ RODRÍGUEZ, A. (Ed.). El Scriptorium alfonsi: de los libros de Astrología a las "Cantigas de Santa María". Madrid: Complutense, 1999.

FIDALGO, Elvira (Coord.). As Cantigas de Loor de Santa María [edición e comentario], Xunta de Galicia-Centro Ramón Piñeiro, 2003.

IMPEY, Olga Tudorica. La fin'amors y sus términos en la prosa histórica de Alfonso X: un caso de reflexión y refracción. Revista Canadiense de Estudios Hispánicos, IX, 3, p. 369-384, 1985.

KELLER, John E. The Motif of the Statue Bride in the Cántigas of Alfonso the Learned. Studies in Philology, LVI, 3, p. 453-458, 1959.

KOENIG, Frédéric. Gautier de Coinci. Les Miracles de Nostre Dame, t. I (20 ed.) y III, Genève: Droz, 1966.

LEWIS, C. S. La alegoría del amor [10 ed. en inglés: 1936], Buenos Aires: EUDEBA, 1969.

METTMANN, Walter (Ed.). Alfonso X, el Sabio. Cantigas de Santa María, tomos I-III, Madrid: Castalia, 1986/ 88/ 89.

MONTOYA MARTÍNEZ, Jesús. Alfonso X el Sabio. Cantigas. Barcelona: Altaya, 1995.

NIERMEYER, J. F. Mediae Latinitatis Lexicon Minus. Leiden: Brill, 1984.

PAREDES NÚÑEZ, Juan (Ed.). Alfonso X el Sabio. Cantigas profanas. Granada: Universidad, 1988.

POWELL JAYNE, Cynthia. The Virgin's Cures for Lust. Estudios alfonsinos y otros escritos. En homenaje a John Esten Keller y a Aníbal Biglieri (ed. N. Toscano Liria), Nueva York: National Hispanic Foundation for Humanities, 1991. p. 118-124.

RIQUER, Martín de. Los trovadores. Historia literaria y textos, III. Barcelona: Planeta, 1975.

SCHAFFER, Martha. Nexus Between the cantiga de amor and the cantiga de Santa Maria: the cantiga "de change". La corónica, 27. 2. 1999.

SNOW, Joseph. The Central Rôle of the Troubadour Persona of Alfonso X in the Cantigas de Santa María. Bulletin of Hispanic Studies, 56, p. 305-316, 1979.

SNOW, Joseph. Alfonso as Troubadour. The Fact and the Fiction. Emperor of Culture. Alfonso X the Learned of Castile and His Thirteenth-Century Renaissance (ed. R. I. Burns), Philadelphia: University of Pennsylvania Press, p. 124-140. 1990. WHINNOM, Keith. Introducción crítica a Cárcel de amor de Diego de San Pedro. Madrid: Castalia, 1971. 


\section{Resumo}

O amor é tratado nas Cantigas de Santa Maria do rei Afonso X em múltiplos níveis: a paixão entre o homem e a mulher fora do matrimônio, o amor cortês (fin' amors), o amor marital entre os esposos que fizeram um juramento, e o amor virginal, eqüivalente à consagração monástica. Nas cantigas de loor, o rei Alfonso apresenta-se como o trovador de Santa Maria e seu entendedor (amante que foi aceito). Mas o estágio final da escala do amor cortês é o da drudaria, que na originalidade afonsina é igualada ao motivo do sponsus marianus.

\section{Abstract}

Love is treated in King Alfonso X's Cantigas de Santa Maria at multiple levels: passion between man and woman out of wedlock, courtly love (fin' amors), marital love between spouses that have made an oath, and virginal love, equivalent to monastic consecration. In the cantigas de loor, King Alfonso presents himself as troubadour of St. Mary and his entendedor (lover whose wooing has been accepted). But the final stage of the courtly love scale is the one of drudaria, which in the alfonsine originality is equalled to the motif of the sponsus marianus. 